Original Article

\title{
Relationship between the use of lower extremity orthoses and the developmental quotient of The Kyoto Scale of Psychological Development in children with Down syndrome
}

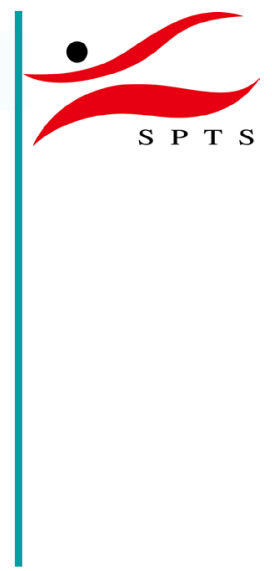

\author{
Yoshihide Kanai, RPT, $\mathrm{PhD}^{1)^{*}}$, Hirotaka Mutsuzaki, MD, $\mathrm{PhD}^{2)}$, \\ Tomohiro Nakayama, MD, $\mathrm{PhD}^{3)}$, Arito Yozu, MD, $\mathrm{PhD}^{4)}$, Nobuaki Iwasaki, MD, PhD \\ 1) Department of Physical Therapy, Ibaraki Prefectural University of Health Sciences: 4669-2 \\ Ami-machi Ami, Inashiki-gun, Ibaraki 300-0394 Japan \\ 2) Department of Orthopaedic Surgery, Ibaraki Prefectural University of Health Sciences, Japan \\ 3) Department of Paediatrics, Ibaraki Prefectural University of Health Sciences Hospital, Japan \\ 4) Department of Rehabilitation Medicine, Ibaraki Prefectural University of Health Sciences, Japan
}

\begin{abstract}
Purpose] The Kyoto Scale of Psychological Development is an evaluation scale developed in the field of psychology. The initial aim of this study was to determine whether the quotient of the Postural-Motor area in the scale was correlated with the use of orthosis in patients with Down syndrome. The second aim was to examine a correlation among Postural-Motor, Cognitive-Adaptive, and Language-Social areas in the participants. [Participants and Methods] Patients with Down syndrome who had received a developmental examination, the Kyoto Scale of Psychological Development, were retrospectively investigated. The sample included 78 participants. Data on the participants' calendar ages ranged from 4.1 to 6.0 years, and the mean age was 4.9 at the examination. The investigated parameters were the number of participants who used an orthosis or insole and the mean developmental quotient for the Postural-Motor, Cognitive-Adaptive, and Language-Social areas. [Results] Twenty participants who completed the exam used an orthosis, and 18 of these had an insole as a first orthosis. The mean Postural-Motor quotient was significantly lower in participants who used an orthosis than in those who did not (52.3 \pm 14.7$)$. [Conclusion] The mean quotient of the Postural-Motor area was significantly lower in patients with Down syndrome who were prescribed some kind of orthosis than in those who were not. There was a significant correlation among the quotients of the three areas. The use of orthosis was expected to positively influence the Cognitive-Adaptive and Language-Social areas through the future in people with Down syndrome who have some difficulty with posture and movement.

Key words: Down syndrome, The Kyoto Scale of Psychological Development (KSPD), Orthosis
\end{abstract}

(This article was submitted Mar. 29, 2018, and was accepted May 7, 2018)

\section{INTRODUCTION}

Patients with Down syndrome (DS) often have orthopaedic complications such as hip dislocation, scoliosis, and upper cervical spine instability ${ }^{1-3)}$. Flat feet are a common orthopaedic problem in people with $\mathrm{DS}^{1,4,5)}$. One study reported that 65 of $85(76.5 \%)$ children with DS met 3 out of 5 criteria for ligament laxity ${ }^{6}$. There is a significant relationship between general joint laxity and flat foot in children with $\mathrm{DS}^{7}$. Children with flat foot are generally prescribed an insole. A study reported the importance of starting a specific rehabilitative programme in early childhood, and recommended the use of proper foot

*Corresponding author. Yoshihide Kanai (E-mail: kanai@ipu.ac.jp)

(C2018 The Society of Physical Therapy Science. Published by IPEC Inc.

(c) (1) $\odot$ This is an open-access article distributed under the terms of the Creative Commons Attribution Non-Commercial No DerivaCC BY NC ND tives (by-nc-nd) License. (CC-BY-NC-ND 4.0: https://creativecommons.org/licenses/by-nc-nd/4.0/) 
insoles for the most severe cases of flat foot ${ }^{8}$. We investigated the number of prescriptions for orthoses in patients with DS. Of the 215 patients, 54 were prescribed an orthosis for the lower extremity, and 47 of these prescriptions were for an insole ${ }^{9}$.

Mental and motor development are generally delayed in people with $\mathrm{DS}^{4}$ ). Postural-motor disorders such as clumsiness and poor co-ordination have also been reported in persons with $\mathrm{DS}^{10,11)}$. People with DS often develop mental and cognitive problems because of Alzheimer's disease and dementia ${ }^{12,13)}$. The degree of cognitive impairment is variable and may be mild, moderate, or occasionally severe, with intelligence quotients of 50-70, 35-50, and 20-35, respectively ${ }^{12}$. A study reported a strong correlation between the Wechsler Intelligence Scale for Children-III (WISC-III) Intelligence Quotient and the Kyoto Scale of Psychological Development (KSPD) developmental quotient (DQ) in children with autism spectrum disorders ${ }^{14)}$. The KSPD was developed in a field of Psychology. That examination evaluates three areas of development, Postural-Movement (P-M), which assesses motor functioning, including fine and gross motor functions, and detects motordevelopment status; Cognitive-Adaptive (C-A), which assesses cognition, including non-verbal reasoning and visuospatial perception; and Language-Social (L-S) which assesses communication, including interpersonal relationships, socialization, and verbal abilities ${ }^{15}$. The KPSD DQ is considered a useful parameter for evaluating children's development. However, the relationship between the P-M DQ and use of lower limb orthoses in children with DS has not been studied. If the association is confirmed, the DQ might be a useful indicator for medical workers in prescribing orthoses for people with DS. The initial aim of this study was to determine whether the quotient of P-M area included in the scale was correlated with the use of orthosis in patients with DS. A second aim of the study was to examine a correlation between P-M, C-A, and L-S area in the participants.

\section{PARTICIPANTS AND METHODS}

All patients with DS who consulted a medical doctor and who conducted the KSPD at Ibaraki Prefectural University Hospital from 1995 to May 2017 were included in this retrospective, population-based study. The study included 78 patients with DS. The participants' calendary ages when assessed by the KSPD ranged from 4.1 to 6.0 years, and the mean age was 4.9 years.

This study was approved by the Ibaraki Prefectural University of Health Sciences Ethics Committee (approval no. 778), and endorsed by the Research Ethics Committee at Ibaraki Prefectural University of Health Sciences Hospital. Participants had the right to opt-out of the study at any time.

As participants with DS generally undergo a developmental examination before they are enrolled in a primary school, we also targeted children with DS in the same age range. Therefore, data from participants aged 4.1 to 6.0 years were included.

Data were collected for the following variables: number of participants who used an orthosis, and the number of participants who used an insole as a first orthosis. Data collected by the KPSD included the mean DQ for the P-M, C-A and L-S areas in all participants, the mean DQ for the three areas in participants who used an orthosis and those who did not use an orthosis, and the mean DQ for the three areas in participants who used an insole and those who did not use an insole. Descriptive statistics were calculated for the study population. The Mann-Whitney U test was used to evaluate the mean DQ of participants in each of the three areas to compare the difference between participants who used orthoses and those who did not. The correlations between the three areas of the KSPD were also calculated. Statistical analyses were performed in SPSS Statistics ver. 24 (IBM SPSS, IBM Corp., NY, USA). The level of statistical significance was set at $\mathrm{p}=0.05$.

\section{RESULTS}

The characteristics of the participants with DS who completed the KSPD are presented in Table 1.

Twenty participants underwent the exam and used an orthosis. Of these, 18 had an insole as a first orthosis, 1 had an ankle-foot orthosis and 1 had a plastic ankle-foot orthosis as a first orthosis.

The mean DQ for participants who used an orthosis and did not are listed in Table 2. There were significant differences in the mean DQ for the P-M area between those with no orthosis and those with an orthosis of any type, and those with only an insole orthosis $(\mathrm{p}<0.05 ; \mathrm{p}<0.05$, respectively). The DQ for the P-M area was significantly lower in participants with an orthosis of any type than in those with no orthosis. No significant differences between the mean DQs for the C-A and L-S areas were found between participants with and without orthoses.

Table 3 shows the correlation coefficients between the mean DQ for each area of the KSPD. The mean DQ for the P-M area was strongly and significantly correlated with that of the $\mathrm{C}-\mathrm{A}$ area $(\mathrm{r}=0.66 ; \mathrm{p}<0.05)$ and moderately and significantly correlated with that of the L-S area $(r=0.57 ; \mathrm{p}<0.05)$. The mean DQ for the C-A area was very strongly correlated with that of the L-S $(r=0.85 ; \mathrm{p}<0.05)$.

\section{DISCUSSION}

The mean DQ of the P-M area was significantly lower in participants who used some kind of orthosis, including an insole, than those who did not. Muscular tone has been reported to be lower in children with DS than in those with typical development $^{16)}$. People with DS suffer from many medical problems, such as muscular hypotonia, ligament laxity, and 
Table 1. Characteristics of participants with Down syndrome who completed The Kyoto Scale of Psychological Development

\begin{tabular}{lc}
\hline Items & Values and numbers \\
\hline Gender (n) & Male: 40; Female: 38 \\
Mean calendary age of participants who underwent KSPD aged 4.1 to 6.0 years & $4.9 \pm 0.6$ \\
Mean DQ of P-M area & $48.5 \pm 16.0$ \\
(n=64; male: 33; female: 31) & \\
Mean DQ of C-A area & $47.5 \pm 13.7$ \\
(n=78; male: 40; female: 38) & \\
Mean DQ of L-S area & $39.3 \pm 12.2$ \\
(n=77; male: 39; female: 38) & \\
Participants who used an orthosis (n) & 20 \\
Ratio (\% of 78 persons) & 25.6 \\
Participants who who used an insole as a first orthosis (n) & 18 \\
Ratio (\% of 78 persons) & 23.7 \\
\hline
\end{tabular}

Values are shown as mean \pm SD.

KSPD: The Kyoto Scale of Psychological Development; DQ: Developmental Quotient; P-M: Postural-Motor; C-A: Cognitive-Adaptive; L-S: Language-Social.

Table 2. Mean Developmental Quotient of The Kyoto Scale of Psychological Development in participants with Down syndrome

\begin{tabular}{|c|c|c|c|c|}
\hline Orthosis & Title of KSPD area for mean DQ & Total & Did not use & Used \\
\hline \multirow{3}{*}{$\begin{array}{l}\text { Insole and other } \\
\text { orthoses for lower } \\
\text { limbs }\end{array}$} & $\begin{array}{l}\text { Mean DQ of P-M area on KSPD } \\
\text { (n=64; did not make: } 47 \text {; did make: } 17 \text { ) }\end{array}$ & $48.5 \pm 16.0$ & $52.3 \pm 14.7$ & $38.1 \pm 15.0^{*}$ \\
\hline & $\begin{array}{l}\text { Mean DQ of C-A area on KSPD } \\
(\mathrm{n}=78 \text {; did not make: } 58 \text {; did make: } 20)\end{array}$ & $47.5 \pm 13.7$ & $48.9 \pm 13.4$ & $43.5 \pm 14.0$ \\
\hline & $\begin{array}{l}\text { Mean DQ of L-S area on KSPD } \\
(\mathrm{n}=77 \text {; did not make: } 57 \text {; did make: } 20)\end{array}$ & $39.3 \pm 12.2$ & $40.7 \pm 12.3$ & $35.3 \pm 11.6$ \\
\hline \multirow{3}{*}{ Insole only } & $\begin{array}{l}\text { Mean DQ of P-M area on KSPD } \\
(\mathrm{n}=62 \text {; did not make: } 47 \text {; did make: } 15)\end{array}$ & $49.5 \pm 15.2$ & $52.3 \pm 14.7$ & $40.9 \pm 13.6^{*}$ \\
\hline & $\begin{array}{l}\text { Mean DQ of C-A area on KSPD } \\
(\mathrm{n}=76 \text {; did not make: } 58 \text {; did make: } 18)\end{array}$ & $48.1 \pm 13.2$ & $48.9 \pm 13.4$ & $45.7 \pm 12.4$ \\
\hline & $\begin{array}{l}\text { Mean DQ of L-S area on KSPD } \\
(\mathrm{n}=75 ; \text { did not make: } 57 \text {; did make: } 18)\end{array}$ & $39.6 \pm 12.2$ & $40.7 \pm 12.3$ & $36.0 \pm 11.5$ \\
\hline
\end{tabular}

Values are shown as mean \pm SD.

KSPD: The Kyoto Scale of Psychological Development; DQ: Developmental Quotient; P-M: Postural-Motor; C-A: Cognitive-Adaptive; L-S: Language-Social.

${ }^{*} \mathrm{p}<0.05$.

Table 3. The correlations between mean Developmental Quotient of each area on The Kyoto Scale of Psychological Development in people with Down syndrome

\begin{tabular}{lccc}
\hline Title of KSPD area & P-M & C-A & L-S \\
\hline P-M $(n=64)$ & - & $0.66^{*}$ & $0.57^{*}$ \\
C-A $(n=78)$ & $0.66^{*}$ & - & $0.85^{*}$ \\
L-S $(n=77)$ & $0.57^{*}$ & $0.85^{*}$ & - \\
\hline
\end{tabular}

$* \mathrm{p}<0.05$.

KSPD: The Kyoto Scale of Psychological Development.

P-M: mean Developmental Quotient of Postural-Motor area on the Kyoto Scale of Psychological Development for participants.

C-A: mean Developmental Quotient of Cognitive-Adaptive area on the Kyoto Scale of Psychological Development for participants.

L-S: mean Developmental Quotient of Language-Social area on the Kyoto

Scale of Psychological Development for participants. 
orthopaedic problems ${ }^{1,6,12)}$. These issues lead to various complications including scoliosis, joint dislocation, weak ankles, and foot problems ${ }^{17)}$. Therefore, patients with a lower DQ in the P-M area may need an orthosis or insole according to our findings. Insoles and orthoses for the lower extremity are generally prescribed for people with foot problems. A study by Puszczałowska et al. found that boys with DS had flatter feet than their healthy peers without $\mathrm{DS}^{18)}$. An insole is often used as a general treatment for flat foot in people with DS to ensure correct foot alignment ${ }^{19)}$. Providing orthotics for boys with DS helped to stabilize them and relieve the overburdened parts of the feet ${ }^{18}$. Our study reported that $23-25 \%$ of the participants were prescribed some kind of orthoses. A previous study mentioned a correlative relationship between ligament laxity and flat foot $^{7}$. Joint laxity has been reported to be present in $76.5 \%$ of children with DS ${ }^{6}$. Our participants who were prescribed orthoses for lower limbs may have medical problems such as ligament laxity and flat foot.

Although there was no significant difference in the mean DQ for the C-A and L-S areas between orthosis groups, the DQ for P-M showed significant positive correlations with the C-A and L-S areas. We expected that ambulation ability would be closely related to these two areas because moving enables people to be exposed to more experiences and to improve their cognitive skills. In a clinical setting, we have observed that children with DS show accelerated improvement in intelligence after becoming mobile. Brain structure and function can influence the development of mental ability ${ }^{13)}$. Bolach reported that the level of intellectual disability had a major influence on motor skills ${ }^{20}$. Therefore, we expected to find a relationship between motor development and cognitive development. The appropriate prescription of insoles for patients would help them to walk properly and thus to develop their cognition. In contrast, children with DS who had a lower level of cognition were also affected by muscle tone and laxity, and they may also have had more severe foot deformities, including flat foot.

A limitation of the present study was that it was retrospectively implemented with a small number of cases. We were unable to find any prospective studies, and thus in future we need to collect prospective data.

In conclusion, the mean quotient of P-M area was significantly lower in patients with Down syndrome who were prescribed to use some kind of orthosis than those who were not. There was a significant correlation between the quotients of the three areas. The use of orthosis was expected to positively influence for C-A and L-S area through the future in people with DS who have some problems of posture and movements.

\section{ACKNOWLEDGEMENT}

We thank Rachel Baron, PhD, from Edanz Group (www.edanzediting.com/ac) for editing a draft of this manuscript.

\section{Funding}

This work was supported by Grant-in-Aid for Community Research 2018 from Ibaraki Prefectural University of Health Sciences.

\section{Conflict of interest}

None.

\section{REFERENCES}

1) Fanter NJ: Down syndrome and orthopaedic problems. Hughston Health Alert, 2012, 24: 1-2.

2) Mik G, Gholve PA, Scher DM, et al.: Down syndrome: orthopedic issues. Curr Opin Pediatr, 2008, 20: 30-36. [Medline] [CrossRef]

3) Selikowitz M: Health problems and health checks in school-aged children with Down syndrome. J Paediatr Child Health, 1992, 28: 383-386. [Medline] [CrossRef]

4) Volman MJ, Visser JJ, Lensvelt-Mulders GJ: Functional status in 5 to 7-year-old children with Down syndrome in relation to motor ability and performance mental ability. Disabil Rehabil, 2007, 29: 25-31. [Medline] [CrossRef]

5) Tanaka H: Orthopaedic complication of Down's syndrome (in Japanese). J Clin Rehabil, 2011, 20: 535-540.

6) Semine AA, Ertel AN, Goldberg MJ, et al.: Cervical-spine instability in children with Down syndrome (trisomy 21). J Bone Joint Surg Am, 1978 , 60: 649-652. [Medline] [CrossRef]

7) Merrick J, Ezra E, Josef B, et al.: Musculoskeletal problems in Down Syndrome European Paediatric Orthopaedic Society Survey: the Israeli sample. J Pediatr Orthop B, 2000, 9: 185-192. [Medline] [CrossRef]

8) Galli M, Cimolin V, Rigoldi C, et al.: The effects of low arched feet on foot rotation during gait in children with Down syndrome. J Intellect Disabil Res, 2014, 58: 758-764. [Medline] [CrossRef]

9) Kanai Y, Mutsuzaki H, Nakayama T, et al.: The prevalence of the flat foot condition and insole prescription in people with Down's syndrome: a retrospective population-based study. J Phys Ther Sci, 2018, 30: 520-524. [Medline] [CrossRef]

10) Vimercati SL, Galli M, Stella G, et al.: Clumsiness in fine motor tasks: evidence from the quantitative drawing evaluation of children with Down Syndrome. J Intellect Disabil Res, 2015, 59: 248-256. [Medline] [CrossRef]

11) Galli M, Cimolin V, Patti P, et al.: Quantifying established clinical assessment measures using 3D-movement analysis in individuals with Down syndrome. Disabil Rehabil, 2010, 32: 1768-1774. [Medline] [CrossRef]

12) Bull MJ Committee on Genetics: Health supervision for children with Down syndrome. Pediatrics, 2011, 128: 393-406. [Medline] [CrossRef] 
13) Malak R, Kostiukow A, Krawczyk-Wasielewska A, et al.: Delays in motor development in children with Down syndrome. Med Sci Monit, 2015 , 21: 1904-1910. [Medline] [CrossRef]

14) Kawabe K, Kondo S, Matsumoto M, et al.: Developmental quotient to estimate intelligence in autism spectrum disorder. Pediatr Int, 2016, 58: 963-966. [Medline] [CrossRef]

15) Koyama T, Osada H, Tsujii H, et al.: Utility of the Kyoto Scale of Psychological Development in cognitive assessment of children with pervasive developmental disorders. Psychiatry Clin Neurosci, 2009, 63: 241-243. [Medline] [CrossRef]

16) Morris AF, Vaughan SE, Vaccaro P: Measurements of neuromuscular tone and strength in Down's syndrome children. J Ment Defic Res, 1982, 26: 41-46. [Medline]

17) Galli M, Cimolin V, Pau M, et al.: Relationship between flat foot condition and gait pattern alterations in children with Down syndrome. J Intellect Disabil Res, 2014, 58: 269-276. [Medline] [CrossRef]

18) Puszczałowska-Lizis E, Nowak K, Omorczyk J, et al.: Foot structure in boys with Down syndrome. BioMed Res Int, 2017: 1-6. [Medline] [CrossRef]

19) Karimi MT, Fereshtehnejad N, Pool F: The impact of foot insole on the energy consumption of flat-footed individuals during walking. Foot Ankle Spec, 2013, 6: 21-26. [Medline] [CrossRef]

20) Bolach B, Bolach E, Drabik M: Differences in motor performance and somatic construction of children with intellectual disability in mild to moderate degrees. Adv Rehabil, 2011, 25: 41-47. [CrossRef] 